\title{
Surgery for Early Stage Invasive Cervical Cancer. Experience of the Oncology Department of Ledantec Hospital
}

\author{
Sidy Ka*, Yaméogo Bonaventure, Mamadou M. Dieng, Souleymane Dieng, Jaafar Thiam, \\ Salif Baldé, Ahmadou Dem
}

Centre Hospitalier Universitaire Le Dantec, Dakar, Sénégal

Email: kasidyoasis@gmail.com

How to cite this paper: Ka, S., Bonaventure, Y., Dieng, M.M., Dieng, S., Thiam, J., Baldé, S. and Dem, A. (2022) Surgery for Early Stage Invasive Cervical Cancer. Experience of the Oncology Department of Ledantec Hospital. Journal of Cancer Therapy, 13, 80-87.

https://doi.org/10.4236/jct.2022.132006

Received: January 8, 2022

Accepted: February 8, 2022

Published: February 11, 2022

Copyright (C) 2022 by author(s) and Scientific Research Publishing Inc. This work is licensed under the Creative Commons Attribution International License (CC BY 4.0).

http://creativecommons.org/licenses/by/4.0/

\section{(c) (i) Open Access}

\begin{abstract}
Background: Surgery is the treatment for early-stage cervical cancer. Radiochemotherapy is used in the treatment of locally advanced stages. But the choice of treatment can be difficult. Objective: The objective of this work was to evaluate the therapeutic aspects of cervical cancer in the early stages IA to IIA in the oncology department of A Ledantec Hospital in Dakar. Patients and methods: This was a descriptive retrospective study, from January 2015 to December 2020, in the oncology department of A Ledantec Hospital, including all the patients who had been treated for early-stage invasive cervical cancer. Results: We included 28 patients. The average age was 49.54 years old. There were 11 patients (39.3\%) with a stage $\leq$ IB1. Surgery was the first in 14 patients (50\%). The initial approach was a midline supra and subumbilical laparotomy. The surgery was R0 in $65.22 \%$. Postoperative complications were found in 4 patients including 1 case of operative wound suppuration, 1 case of dysuria, 1 case of postoperative eventration and 1 case of rectovaginal fistula. Concomitant Radiochemotherapy was neoadjuvant in 7 cases (25\%), adjuvant in 14 cases (50\%). The chemotherapy was neoadjuvant in 09 cases (56.25\%) and adjuvant in 7 cases (43.75\%) with minor toxicities. We had recorded 2 deaths. Conclusion: The treatment of the early stages of invasive cervical cancer is based on surgery. Neoadjuvant treatments may be useful in particular situations.
\end{abstract}

\section{Keywords}

Cancer, Cervix, Early, Treatment

\section{Introduction}

Treatment for cervical cancer depends on the stage. The operable early stages IA 
and IB1 are resected and locally advanced stages from IB2 onwards benefit from concomitant radiochemotherapy [1] [2]. The difficulty of evaluating certain cases and the choice of certain teams show a difference in the treatment choices. Beyond stage IB2 the cancer is locally advanced. Certain situations, in particular the unavailability of radiotherapy and comorbidities, may require the choice of neoadjuvant chemotherapy or radiotherapy. The objective of this work was to evaluate the therapeutic aspects of cervical cancer in the early stages IA to IIA in the oncology department of A Ledantec Hospital in Dakar.

\section{Patients and Methods}

This was a descriptive retrospective study in the oncology department of A Ledantec Hospital in Dakar. It took place from January 2015 to December 2020, a period of 6 years. We included all patients treated for histologically confirmed invasive cervical cancer, early stage IA to IB1 and extended to IIA. All patients were listed and discussed in multidisciplinary tumor board. The data was collected on a collection sheet. They are then transposed on excel and then processed on SPSS. Overall survival was calculated using the Kaplan Meier method. Comparative survival was calculated using the Log Rank method. The $\mathrm{p}$ value was considered significant for a value less than 0.05 .

\section{Results}

We had registered a total of 28 patients with early invasive cervical cancer over 6 years. The mean age of the patients was $49.54 \pm 8.96$.

\subsection{Tumor Size}

The tumor was clinically palpable on vaginal examination in 23 patients with a mean size of $2.71 \pm 1.36 \mathrm{~cm}[0.6 ; 7 \mathrm{~cm}]$. The tumor size was $\leq 2 \mathrm{~cm}$ in 11 patients (39.29\%) (Figure 1).

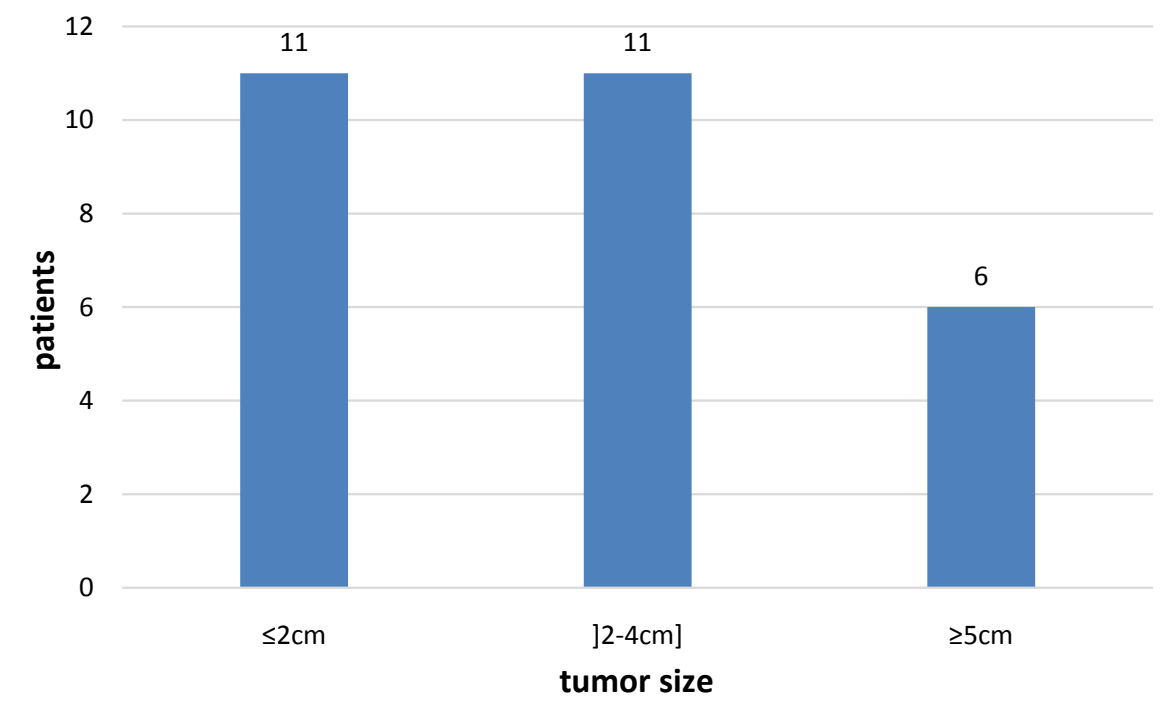

Figure 1. Distribution of patients according to tumor size. 


\subsection{Clinical Stage}

Stage IB2 was the most represented, i.e. $39.3 \%(\mathrm{n}=11)$ followed by stage IB1 (Figure 2).

\subsection{Indications for Surgery}

Surgery was the first treatment in 14 patients (50\%). It was post-radiochemotherapy in 06 patients (22\%), post-chemotherapy alone in 07 patients $(8.7 \%)$ and postradiotherapy alone in 1 patient (3.6\%). The initial approach was a midline supra and subumbilical laparotomy. The actions performed are summarized in Table 1.

\subsection{Quality of Surgery}

Surgery was complete in $60.7 \%(\mathrm{n}=17)$ of cases. On histology, surgery was R0 in $71.4 \%$ of cases $(n=20), R 1$ in $25 \%$ of cases $(n=7)$ and $R 2$ in $3.5 \%$ of cases $(n=$ 1) $(\mathrm{p}=0.27)$. The mean number of lymph nodes on dissection was $7.27 \pm 6.36$. The mean number of lymph nodes invaded was $0.23 \pm 0.75$ [ 0 and 3]. Two operated patients presented with 3 and 2 lymph nodes, respectively, for stages IB2 and IIA. The number of lymph nodes invaded related to FIGO stage is shown in Table 2.

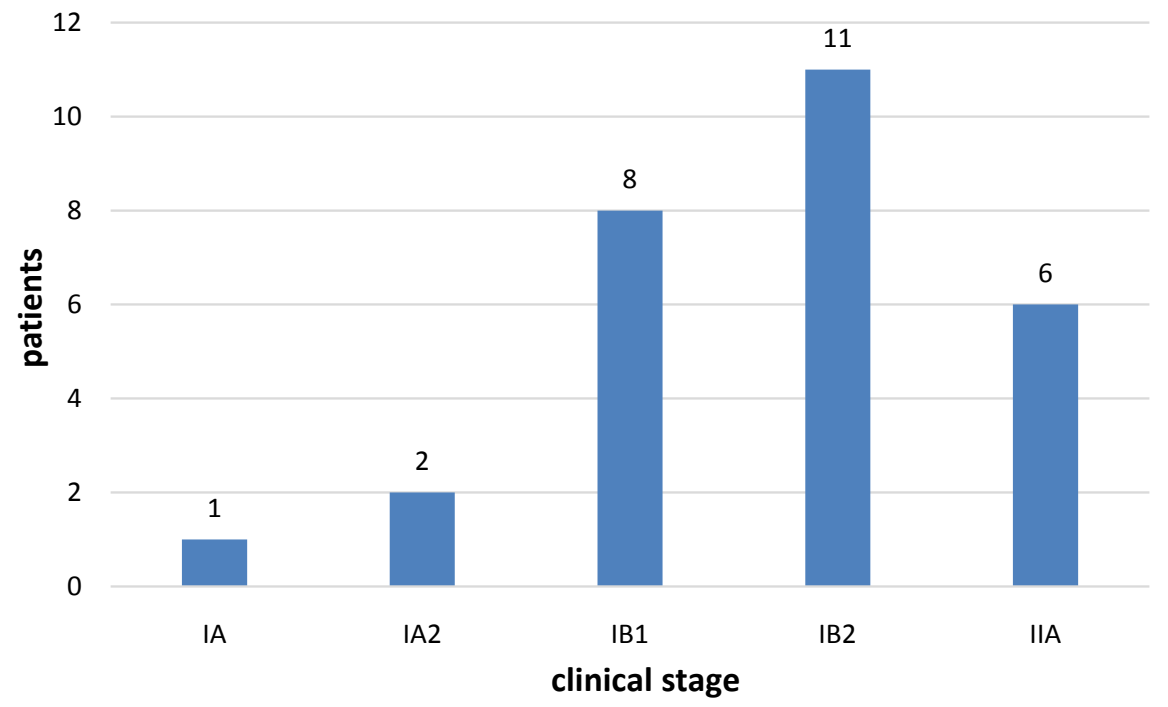

Figure 2. Distribution of patients according to clinical stage.

Table 1. Types of surgery.

\begin{tabular}{ccc}
\hline Type of surgery & $\mathrm{n}$ & $\%$ \\
\hline Hysterectomy & 1 & 3.5 \\
Hysterectomy + oophorectomy & 5 & 17.85 \\
Tysterectomy + oophorectomy + pelvic node dissection & 22 & 78.57 \\
Total & 28 & 100 \\
\hline
\end{tabular}


Table 2. Lymph node involvement according to clinical stage.

\begin{tabular}{ccccc}
\hline FIGO stage & $0 \mathrm{~N}+$ & $1 \mathrm{~N}+$ & $2 \mathrm{~N}+$ & $3 \mathrm{~N}+$ \\
\hline IA & 1 & 0 & 0 & 0 \\
IA2 & 2 & 0 & 0 & 0 \\
IB1 & 8 & 0 & 0 & 0 \\
IB2 & 11 & 0 & 0 & 1 \\
IIA & 6 & 0 & 1 & 0 \\
Total & 28 & 0 & 1 & 1 \\
\hline
\end{tabular}

\subsection{Adjuvant Treatment}

Radiotherapy was adjuvant in 14 cases $(50 \%)$. In $50 \%$ of cases $(n=14)$, concomitant adjuvant radio-chemotherapy was necessary due to unfavorable criteria, such as parametrial involvement, an affected margin, significant stromal invasion, or the existence of lymph node metastases.

The mean dose administered was $60.47 \pm 7.44$ Gray [46; 66 Gray]. A complete clinical response was noted in 19 patients $(82.61 \%)(n=23)$ and partial in 04 patients. The side effects of radiotherapy were 01 case $(4.35 \%)$ of vaginal synechia, and 03 cases (13.04\%) of grade 2 digestive toxicity.

- Chemotherapy

It was effective in $57.14 \%$ of cases $(n=16)$. It was adjuvant in 07 cases (43.75\%). The most used protocol was the Carboplatin-paclitaxel protocol in all patients $(n=16)$. The response was complete in $87.5 \%$ of cases $(n=14)$.

\subsection{Operative Complications}

No intraoperative incident was notified during the various surgical procedures.

The postoperative course was marked by complications in 4 cases (14.3\%).

Postoperative complications were divided into early, secondary and late.

- Early complications:

1 case of suppuration of the abdominal occurred on day 3 .

- Secondary complications:

1 functional urinary disorder, such as dysuria, was found in one (01) patient.

- Late complications:

1 rectovaginal fistula was noted. The patient presented with stage IIA squamous cell carcinoma of the cervix having undergone radiotherapy alone 66 gray followed by R1 surgical resection without pelvic dissection due to post-radiation fibrosis. An elective colostomy was therefore performed.

1 case of postoperative eventration was noted.

\subsection{Survival}

Mortality was $7.14 \%(\mathrm{n}=2)$. Bilateral centro-pelvic and iliac recurrence was diagnosed at month 19 . Nine (09) cases of recurrence were noted within a mean period of $26.33 \pm 09.24$ months. 
The overall survival of the patients was $28.78 \pm 12.77$ months [5; 64 months].

For patients who had surgery as first treatment $(\mathrm{n}=14)$, survival was $28.56 \pm$ 16.40 months [12; 64 months], median at 27 and $27.59 \pm 16.29$ months [5; 64 months], median at 26 for patients having had post-radiochemotherapy surgery $(\mathrm{n}=7) ;(\mathrm{p}=0.46)$.

\section{Discussion}

\subsection{Primary Surgery}

Surgery remains the standard treatment for invasive early cervical cancers (IB1 or IIA1), based on radical hysterectomy associated with pelvic dissection [1] [3]. There is no data showing the superiority of surgery over radiotherapy and the likelihood that patients will require additional radiotherapy due to negative risk factors is high [4]. The sentinel node technique has been prospectively evaluated in early stage cervical cancers and the Senticol-1 study demonstrated the feasibility of this technique [5]. To date, dissection remains the gold standard for assessing lymph node status. Tumor size has little influence on the choice of surgery. It seems to influence the choice of radiotherapy [6].

\subsection{Surgery after Neoadjuvant Treatment}

Concurrent radiochemotherapy $(\mathrm{CRC})$ is the benchmark in locally advanced stages. In the early stages, even in cases of non-inferiority, morbidity is a sufficient argument for the choice of surgery. It is not clear whether patients with stage IB2 or IIA2 cervical cancer can first receive chemotherapy and then have a hysterectomy, even under certain conditions. However neoadjuvant treatments can allow tumor volume and bleeding regression [7].

\subsection{Surgery and Radiotherapy}

There is no data showing the superiority of surgery over radiation therapy and the likelihood that patients will require additional radiation therapy due to negative risk factors is high. For patients who develop recurrent disease after definitive surgery and who have not received previous radiation therapy, salvage radiation therapy is the treatment of choice. And patients who have received definitive primary radiation therapy are candidates for surgical resection [8]. The use of brachytherapy seems to lead to a very low rate of local relapses, a risk of parametrial damage of the order of $0.5 \%$ and a completely acceptable safety profile, without an increase in operative morbidity [9] [10].

\subsection{The Results of the Surgery}

On the carcinological level, the state of the surgical margins does not correlate with the prognosis because of the potential use of adjuvant radiotherapy [11]. The complications of radical hysterectomy are numerous. Lesions of the genitourinary system are in the order of $1 \%$ to $2 \%$ [12] [13]. Considering the surgical way, the risk of bladder and ureteral injury is higher with laparoscopic hyste- 
rectomy than with abdominal hysterectomy [14].

Ureteral lesions are generally less common than bladder lesions because their incidence is underestimated. Studies show that around $66 \%$ of ureteral lesions are unrecognized intraoperatively [15]. Recto-vaginal fistulas are rarer, but their repair is more difficult. They are seen especially in the event of very extensive surgery and if radiotherapy has been administered. Their diagnosis is easy and repair should be postponed [16]. Regarding the quality of sex life, several women have reported sexual dysfunctions after radical hysterectomy. Dyspareunia, anorgasmia and vaginal dryness have been reported [17] [18].

\subsection{Adjuvant Treatment}

It is not systematic, it depends on the histological results of the surgery and follow up. In the event of incomplete surgery, progressive continuation or recurrence, radiotherapy or radiochemotherapy are more indicated than salvage surgery.

\subsection{The Survival}

The difference in terms of overall survival at five or ten years is not significant in patients with stage IB2, IIA or IIB disease treated with radiotherapy alone and radiotherapy followed by surgery $(p>0.5)$ [19]. Surgery may reduce the rate of local recurrence, especially in patients with tumors larger than $4 \mathrm{~cm}$ [20]. Positive lymph nodes are an independent prognostic factor for overall survival [21]. A high rate of extra cervical disease and pelvic and/or para-aortic lymph node involvement is associated with a decrease in overall survival despite a complete response after chemoradiotherapy [22].

The limitations of the work are above all the inconstancy of the availability of radiotherapy; This resulted in the exclusion of some patients from the study.

\section{Conclusion}

Surgery is the essential treatment for the early stages of cervical cancer. For more advanced stages, concomitant radiochemotherapy is recommended. Surgery can be a recourse in the event of recurrence. The carcinological prognosis is good. But the complications and sequelae are still numerous. Hence the interest is in developing less invasive surgical methods and promoting prevention.

\section{Acknowledgements}

We thank the radiation therapy unit for their collaboration

\section{Authors' Contributions}

All the authors contributed to the workup of the patient including clinical evaluation, investigation, and treatment planning. The manuscript has been reviewed and approved by all the authors. 


\section{Conflicts of Interest}

The authors declare that they have no competing interests.

\section{References}

[1] Meigs, J.V. (1951) Radical Hysterectomy with Bilateral Pelvic Lymph Node Dissections; a Report of 100 Patients Operated on Five or More Years Ago. The American Journal of Obstetrics and Gynecology, 62, 854-870. https://doi.org/10.1016/0002-9378(51)90175-5

[2] Naga, C.P., Gurram, L., Chopra, S. and Mahantshetty, U. (2018) The Management of Locally Advanced Cervical Cancer. Current Opinion in Oncology, 30, 323-329. https://doi.org/10.1097/CCO.0000000000000471

[3] Cibula, D., Pötter, R., Planchamp, F., Avall-Lundqvist, E., Fischerova, D., Meder, C.H., et al. (2018) The European Society of Gynaecological Oncology/European Society for Radiotherapy and Oncology/European Society of Pathology Guidelines for the Management of Patients with Cervical Cancer. International Journal of Gynecological Cancer, 28, 641-655. https://doi.org/10.1097/IGC.0000000000001216

[4] Landoni, F., Maneo, A., Cormio, G., Perego, P., Milani, R., Caruso, O., et al. (2001) Class II versus Class III Radical Hysterectomy in Stage Ib-IIa Cervical Cancer: A Prospective Randomized Study. Gynecologic Oncology, 80, 3-12. https://doi.org/10.1006/gyno.2000.6010

[5] Bats, A.S., Frati, A., Froissart, M., Orliaguet, I., Querleu, D., Zerdoud, S., et al. (2015) Feasibility and Performance of Lymphoscintigraphy in Sentinel Lymph Node Biopsy for Early Cervical Cancer: Results of the Prospective Multicenter SENTICOL Study. Annals of Nuclear Medicine, 29, 63-70. https://doi.org/10.1007/s12149-014-0910-1

[6] Vetter, M.H., Smrz, S., Gehrig, P.A., Peng, K., Matsuo, K., et al. (2020) Pathologic and Clinical Tumor Size Discordance in Early-Stage Cervical Cancer: Does It Matter? Gynecologic Oncology, 159, 354-358.

https://doi.org/10.1016/j.ygyno.2020.08.004

[7] Peng, Y.H., Wang, X.X., Zhu, J.S. and Gao, L. (2016) Neo-Adjuvant Chemotherapy plus Surgery versus Surgery Alone for Cervical Cancer: Meta-Analysis of Randomized Controlled Trials. Journal of Obstetrics and Gynaecology Research, 42, 128 135. https://doi.org/10.1111/jog.12896

[8] Leitao, M.M. and Chi, D.S. (2002) Recurrent Cervical Cancer. Current Treatment Options in Oncology, 3, 105-111. https://doi.org/10.1007/s11864-002-0056-6

[9] Escande, A., Gouy, S., Mazeron, R., Bentivegna, E., Bacorro, W., Maroun, P., et al. (2017) Outcome of Early Stage Cervical Cancer Patients Treated According to a Radio-Surgical Approach: Clinical Results and Prognostic Factors. Gynecologic Oncology, 144, 541-546. https://doi.org/10.1016/j.ygyno.2016.12.026

[10] Escande, A., Mazeron, R., Gouy, S., Bentivegna, E., Maroun, P., Fahra, G., et al. (2016) Preoperative Image-Guided Brachytherapy in Early Stage Cervical Cancers. Radiotherapy and Oncology, 120, 455-459. https://doi.org/10.1016/j.radonc.2016.07.003

[11] Kimmig, R. and Ind, T. (2018) Minimally Invasive Surgery for Cervical Cancer: Consequences for Treatment after LACC Study. Journal of Gynecologic Oncology, 29, e75. https://doi.org/10.3802/jgo.2018.29.e75

[12] Clarke-Pearson, D.L. and Geller, E.J. (2013) Complications of Hysterectomy. Obstetrics \& Gynecology, 121, 654-673. https://doi.org/10.1097/AOG.0b013e3182841594 
[13] Walters, M.D. and Karram, M.M. (2007) Urogynecology and Reconstructive Pelvic Surgery. 3rd Edition, Mosby Elsevier, Philadelphia, 413-424. https://doi.org/10.1016/B978-0-323-02902-5.50038-1

[14] Johnson, N., Barlow, D., Lethaby, A., Tavender, E., Curr, E. and Garry, R. (2006) Surgical Approach to Hysterectomy for Benign Gynaecological Disease. Cochrane Database of Systematic Reviews, 19, CD003677. https://doi.org/10.1002/14651858.CD003677.pub2

[15] Gilmour, D.T., Dwyer, P.L. and Carey, M.P. (1999) Lower Urinary Tract Injury during Gynecologic Surgery and Its Detection by Intraoperative Cystoscopy. Obstetrics \& Gynecology, 94, 883-889. https://doi.org/10.1097/00006250-199911001-00045

[16] Garabedian, C., Merlot, B., Bresson, L., Tresch, E., Narducci, F. and Leblanc, E. (2015) Minimally Invasive Surgical Management of early-Stage Cervical Cancer: An Analysis of the Risk Factors of Surgical Complications and of Oncologic Outcomes. International Journal of Gynecological Cancer, 25, 714-721. https://doi.org/10.1097/IGC.0000000000000390

[17] Maas, C.P., Weijenborg, P.T. and ter Kuile, M.M. (2003) The Effect of Hysterectomy on Sexual Functioning. Annual Review of Sex Research, 14, 83-113.

[18] Fidan, U., Keskin, U., Ulubay, M., Öztürk, M. and Bodur, S. (2017) Value of Vaginal Cervical Position in Estimating Uterine Anatomy. Clinical Anatomy, 30, 404-408. https://doi.org/10.1002/ca.22854

[19] Perez, C.A., Grigsby, P.W., Camel, H.M., Galakatos, A.E., Mutch, D. and Lockett, M.A. (1995) Irradiation seule ou associee a une intervention chirurgicale au stade IB, IIA et IIB carcinome du col uterin: Mise à jour d'une comparaison non randomisee. International Journal of Radiation Oncology, Biology, Physics, 31, 703-716. https://doi.org/10.1016/0360-3016(94)00523-0

[20] Keys, H.M., Bundy, B.N., Stehman, F.B., Okagaki, T., Gallup, D.G., Burnett, A.F., Rotman, M.Z. and Fowler, W.C. (2003) Radiotherapie avec et sans hysterectomie extrafasciale pour le cancer du col uterin du stade IB volumineux: Un essai randomise du groupe d'oncologie gynecologique. Gynecologic Oncology, 89, 343-353. https://doi.org/10.1016/S0090-8258(03)00173-2

[21] Touboul, C., Uzan, C., Mauguen, A., Gouy, S., Rey, A., Pautier, P., Lhomme, C., Duvillard, P., Haie-Meder, C. and Morice, P. (2010) Cancer du col uterin. Oncologiste, 15, 405-415. https://doi.org/10.1634/theoncologist.2009-0295

[22] Azria, E., Morice, P., Haie-Meder, C., Thoury, A., Pautier, P., Lhomme, C., Duvillard, P. and Castaigne, D. (2005) Resultats de l'hysterectomie chez les patients presentant une maladie residuelle volumineuse à la fin de la chimioradiotherapie pour le carcinome cervical de stade IB2 I II. Annals of Surgical Oncology, 12, 332-337. https://doi.org/10.1245/ASO.2005.05.020 